\title{
INVESTIGATION OF PROPERTIES OF NANOFIBERS FROM COLLAGEN AND POLYETHYLENE TEREPHTHALATE USING A NATURAL CROSS-LINKER
}

\author{
MIOARA DROBOTA, ${ }^{*}$ STELIAN VLAD, ${ }^{*}$ LUIZA GRADINARU, \\ MARIA BUTNARU* and GRATIELA PIRCALABIORU** \\ " "Petru Poni” Institute of Macromolecular Chemistry, 41A, Gr. Ghica-Voda Alley, \\ 700487 Iasi, Romania \\ ** Sanimed International Impex S.R.L, 70F, Bucharest-Măgurele Road, Bucharest, Romania \\ \Corresponding authors: Stelian Vlad,vladus@icmpp.ro \\ Mioara Drobota, miamiara@icmpp.ro
}

Received November 1, 2018

\begin{abstract}
The study highlights the properties of nanofibers obtained from collagen and polyethylene terephthalate solution, crosslinked with riboflavin by in situ UV irradiation. The nanofiber morphology was characterized by Static Contact Angle Measurements and Scanning Electron Microscopy (SEM). Mechanical characterization and Fourier Transform Infrared Attenuated Total Reflectance (FTIR-ATR) spectroscopy indicated different specific structures. The preliminary cell growth tests were also performed and the cell morphology was observed. Our results suggest that these materials could be used in various biomedical applications.
\end{abstract}

Keywords: electrospinning, collagen, polyethylene terephthalate, riboflavin

\section{INTRODUCTION}

The combination of natural and synthetic components give the possibility of obtaining many composites with improved properties. ${ }^{1-3}$ The optimal features of nanofibers obtained from natural materials promote cell repopulation and formation of new tissue. Collagen type $I$ is the most abundant protein in the extracellular matrix and also in the human body, it is a fibrillar protein with a long and rigid structure that provides the mechanical and physical characteristics of tissues. Collagen, as part of native tissues, is most utilized to fabricate scaffolds, serving as an active analogue of native regeneration for dermal reconstruction. ${ }^{4}$ Electrospun nanofibers of natural or synthetic polymers, with a three-dimensional structure, were chosen for applications in tissue engineering to achieve good cell adhesion and proliferation. In tissue engineering, it is important to produce natural fibers with nanometric dimensions, because they offer a well-defined architecture, promote the formation of tissues and increase the regeneration rate of tissues, compared to any other known fiber types. Electrospinning is a very useful technique for producing polymeric nanofibers by applying electrostatic forces to obtain a positive charge of the polymer solution in a filament. ${ }^{5-7}$ An optimum solvent system is a crucial factor for successfully obtaining electrospun nanofibers. The electrospinning procedure is an efficient, convenient and flexible process, known to produce fibers, from different components: polycaprolactone (PCL), polyethylene oxide (PEO), collagen, poly(ethylene terephthalate), cellulose, cellulose acetate etc. ${ }^{8,9}$

By electrospinning, composite nanofibers can be fabricated by blending different compatible polymers in a solution. ${ }^{10,11}$ The fibers are formed from a liquid droplet, deformed into a cone (called Taylor cone), which turns into a jet of liquid from the tip of a syringe and moving towards a grounded collector. The possibility to change the chemical composition of electrospun fibers according to the targeted application is extremely important in the tissue engineering field. ${ }^{12,13}$ 
Riboflavin (RIBO), also known as vitamin B2, plays a significant role in the metabolization of carbohydrates, protein, generating energy. Riboflavin exhibits an important role in cell growth and reproduction, regeneration and growth of tissues. ${ }^{14-16}$

In this study, a solution of collagen, polyethylene terephthalate and a mixture of the two were electrospun and the samples were denoted as follows: COL, PET and PET-COLRIBO, respectively.

Physical methods are considered to be good cross-linking alternatives because the materials come into contact with the solvents and under solid-state conditions can be effective. The nanofibers obtained from the blend of collagen and polyethylene terephthalate were cross-linked using riboflavin through UV irradiation. ${ }^{17-19}$ The nanofibers (PET-COL-RIBO) from the blend solution were stabilized photochemically.

Static contact angle measurements provide valuable information about the surface of the nanofibers. Thus, based on these measurements, some surface parameters could be calculated.

Knowing the mechanical properties of newly developed materials is crucial for future tissue regeneration. For finding out the architecture of the new biomaterials fabricated from collagen and different polymers or biopolymers, it was necessary to study the mechanical properties and compare them with those of individual components.

The interaction between the nanofiber materials fibroblast cells was then assessed, and the results obtained were satisfactory.

\section{EXPERIMENTAL}

\section{Materials}

A polyethylene terephthalate (PET) film (Mw\% 80000) was obtained from Terom Romania. Collagen type I (COL), riboflavin (RIBO) (B2 vitamin) and 1,1,1,3,3,3-hexafluoro-2-propanol (HFIP) were purchased from Sigma-Aldrich (Singapore). Hank's Balanced Salt Solution (HBSS) for cell culture, 3-(4,5dimethyl-2-thiazolyl)-2,5-diphenyl-2H, $\quad 4 \%$ paraformaldehyde solution in HBSS and absolute alcohol were also purchased from Sigma-Aldrich (Singapore). Fibroblasts were provided by the laboratory of Tissue Engineering and Regenerative Medicine, Grigore T. Popa University of Medicine and Pharmacy of Iasi. The cells were isolated by the explant method from Albino rabbit skin dermis, according to the animal welfare requirements and ethical approval of the Ethical Committee of the Grigore T. Popa University of Medicine and Pharmacy of Iasi.

\section{Electrospinning procedure}

Two homogeneous solutions of $10 \%$ (w/w) COL and PET were prepared. Different PET:COL ratios were tested for electrospinning and the optimum of 1:1 (v/v) was chosen. For stabilizing the nanofibers, $5 \mathrm{wt} \%$ riboflavin was added, with respect to the PET-COL blend. All the solutions were homogenized at ambient temperature by continuous magnetic stirring for 2 hours. After that time, it was observed that the solution had high clarity and presented no flocs, so the stirring was stopped.

The polymer solution was used to fill a standard 10 $\mathrm{mL}$ syringe provided with a blunt needle, which was coupled to a high voltage power supply in the range of $10-30 \mathrm{kV}$. The distance between the tip of the needle and the collector drum was adjusted to $10 \mathrm{~cm}$ to get nanofibers. A G20 needle tip was used with an inner diameter of $0.58 \mathrm{~mm}$. At an optimal value of $15 \mathrm{kV}$, the PET-COL-RIBO polymer solution was deposited on the collector as nanofiber film.

All the electrospun nanofibers were collected at room temperature. For the stabilization of the PETCOL-RIBO sample, a UV lamp (Herolab $\mathrm{GmbH}$, Germany) was used. The UV lamp ( $8 \mathrm{~W})$, at an intensity of $950 \mu \mathrm{W} / \mathrm{cm}^{2}$, was placed above of the electrospinning system and used during the electrospinning process. Under UV irradiation, the cross-linking and stabilization of the system were initiated by the riboflavin compound. The obtained nanofibers were dried at room temperature and then characterized.

UV light was utilized to produce riboflavin radicals, leading to cross-linking at $365 \mathrm{~nm}$ wavelength (maximum absorption for riboflavin). The stabilization by UV cross-linking was used to increase the mechanical strength of nanofibers. After the stabilization period, the dry fibers were stored at room temperature for 2 days.

The electrospinning process depends on some factors, such as solution concentration, electrical voltage, flow, needle size and the distance between the needle and the collector. The obtained nanofibers may be randomized or aligned in the film structure by varying the electrospinning setups. Therefore, the electrospinning parameters were varied in order to obtain good fiber mats of COL, PET and PET-COLRIBO, respectively.

Therefore, different specimens of fibers of PET, COL and PET-COL-RIBO were developed by varying chosen parameters. The surface of the electrospun mats increased with a decrease in fiber diameter, and the free space between the layers of nanofibers influenced the volumetric density.

\section{Methods}

\section{Static contact angle measurements}

Static contact angle measurements were performed by using a CAM 101 (KSV Instruments, Helsinki, Finland) system, equipped with a liquid dispenser, 
video camera and drop shape analysis software. Two experimental liquids - double-distilled water and ethylene glycol were used, and for each kind of liquid, three different regions were selected to obtain statistical results. All the measurements were performed at room temperature.

\section{Scanning Electron Microscopy Imaging (SEM)}

Nanofiber mats were examined using a FEI Quanta 200 scanning electron microscope. Surface morphology was performed in a high-vacuum microscope chamber, at an accelerating voltage of 20 $\mathrm{kV}$. For each nanofiber film, several measurements were performed and the results were analyzed.

\section{Mechanical properties}

The tensile properties of polymeric films were performed on Instron apparatus (INSTRON model 3365; Universal Testing Machine, INSTRON, US), with a load cell of $500 \mathrm{~N}$, on dumbbell-shaped cut samples (sample dimensions: $50 \times 8.5 \times 4 \mathrm{~mm}$ ). The tensile stress measurements were performed at different extension rates (from $1 \mathrm{~mm} / \mathrm{min}$ to 30 $\mathrm{mm} / \mathrm{min})$.

\section{Fourier Transform infrared-Attenuated total} reflectance spectroscopy (FTIR-ATR)

The structure of all the electrospun samples was investigated using a Bruker LUMOS - FT-IR Microscopy with an ATR module (attenuated total reflection), with a diamond crystal with single reflection fixed at an incidence angle of $45^{\circ}$. The spectra were recorded at a resolution of $2 \mathrm{~cm}^{-1}$, with a number of 64 scans, to improve the signal/noise ratio.

\section{Cell morphology evaluation}

Cell morphology was evaluated by SEM analysis. For investigating the population of the material with cells, the polymeric sample was cut using a $10 \mathrm{~mm}$ biopsy punch, sterilized for $40 \mathrm{~min}$ in $70 \%$ aqueous ethanol solution, washed twice in sterile doubledistilled water, three times in sterile phosphate buffer (HBSS, Sigma) and twice in DMEM media. After washing, each material was equilibrated in $2 \mathrm{~mL}$ of DMEM, supplemented with $10 \%$ BFS and $1 \%$ PSN, at $37{ }^{\circ} \mathrm{C}$ and $5 \% \mathrm{CO}_{2}$ atmosphere for at least $24 \mathrm{~h}$. The sterilized and equilibrated polymer pieces were placed on the bottom of the 48 -well culture plate. Over the polymer, the fibroblast suspension of $2 \times 10^{4}$ cells/material piece was added. The fibroblasts on the material surface were cultured at $37{ }^{\circ} \mathrm{C}$ and $5 \% \mathrm{CO}_{2}$ atmosphere for 72 hours. The polymer samples populated with cells were thoroughly washed in HBSS solution and added to a $4 \%$ paraformaldehyde fixator solution for at least 24 hours. After fixation, the polymer samples were dehydrated in alcohol baths with increasing concentration $(30 \%, 50 \%, 70 \%, 90 \%$ and $100 \%)$ and dried. Dried polymer samples were further coated with gold for SEM examination.

\section{RESULTS AND DISCUSSION}

In this paper, the properties of nanofibers obtained from native collagen, polyethylene terephthalate and their blend, cross-linked with riboflavin by in situ UV irradiation were studied.

\section{Surface characterization}

Generally, contact angle values can be used to estimate the surface tension of a solid. Therefore, in order to evaluate the wettability of the electrospun films and to calculate the surface parameters, static contact angle measurements were performed. The experimental values of all the samples are shown in Table 1. It is observed that the electrospun samples have different wettability. Thus, COL nanofibers are hydrophilic with a contact angle value with water of about 67 degrees, while PET-nanofibers are hydrophobic with a value of 131.84 degrees. When these two compounds were blended and UV cross-linked with riboflavin (PET-COL-RIBO nanofibers), it was observed that the nanofiber samples exhibited more hydrophilic properties, with a contact angle value of about 24.95 degrees. This variation in the contact angle values of the electrospun samples may be due to the chemical structures of the polymers, as well as to the "gaps" among the nanofibers formed during electrospinning. Based on these measurements, it is possible to calculate the parameters characterizing the surface of the solid and its absorption capacity (wettability), such as free surface energy $\left(\gamma_{\mathrm{Sv}}\right)$, solid-liquid interfacial tension $\left(\gamma_{\mathrm{SL}}\right)$, work of adhesion $(\mathrm{Wa})$ etc.

Free surface energy $\left(\gamma_{\mathrm{SV}}\right)$ was determined by the Owens-Wendt-Rabel and Kaelbe method. ${ }^{20}$ This energy is the sum of the contributions of various surface intermolecular forces, such as dispersion and polar forces. ${ }^{21}$ If the value of a component decreases, the other will increase depending on the number of functional groups present on the polymer surface. From Table 1, it is observed that the values of the dispersive components for the COL and PET nanofiber samples are higher compared to the polar component, which allows concluding that there are more hydrophobic groups than hydrophilic ones on the polymer surfaces. In contrast, the electrospun PET-COL-RIBO shows a higher value for the polar component than for the dispersive one.

The work of adhesion $\left(\mathrm{W}_{\mathrm{a}}\right)$ can be also calculated from the contact angle data. Generally, $\mathrm{W}_{\mathrm{a}}$ of the electrospinning samples decreases with 
the increasing of the contact angle values. With the exception of PET nanofibers, the other two, PET-COL-RIBO and COL nanofibers, present higher $\mathrm{W}_{\mathrm{a}}$.

The interfacial energy value may be high or low, depending on the attractive forces between the liquid molecules and the solid surface. Thus, if the attractive forces between the liquid molecules and those from the polymer surface are lower, then the energy value is higher and the liquid drop will adhere less to the surface. ${ }^{22} \mathrm{COL}$ and PET-COL-RIBO nanofibers have smaller values of the interfacial energy than PET nanofiber samples, owing to the lower values of the water contact angles.

\section{SEM analysis}

The surface morphology of the obtained nanofiber films was investigated by SEM. The morphology of PET-COL-RIBO was compared with those of COL and PET nanofiber structures, obtained by the same electrospinning process. SEM images indicate that the obtained fibers are at the nanoscale level (Fig. 1). Thus, the dimensions of COL fibers vary between 120-450 $\mathrm{nm}$, those of PET nanofibers between 80-500 nm, and those of PET-COL-RIBO between 150-250 $\mathrm{nm}$, respectively. It is also observed that the nanofibers are relatively homogeneous, without processing defects.

Table 1

Surface parameters of nanofibers

\begin{tabular}{|c|c|c|c|c|c|c|c|}
\hline \multirow{2}{*}{ Samples } & \multicolumn{2}{|c|}{ Contact angle } & \multirow{2}{*}{$\begin{array}{c}\mathrm{W}_{\mathrm{a}} \\
(\mathrm{mN} / \mathrm{m})\end{array}$} & \multirow{2}{*}{$\begin{array}{c}\gamma_{\mathrm{SV}} \\
(\mathrm{mN} / \mathrm{m})\end{array}$} & \multirow{2}{*}{$\begin{array}{c}\gamma^{\mathrm{P}} \mathrm{sV} \\
(\mathrm{mN} / \mathrm{m})\end{array}$} & \multirow{2}{*}{$\begin{array}{c}\gamma_{\mathrm{sV}}^{\mathrm{d}} \\
(\mathrm{mN} / \mathrm{m})\end{array}$} & \multirow{2}{*}{$\begin{array}{c}\gamma_{\mathrm{SL}} \\
(\mathrm{mN} / \mathrm{m})\end{array}$} \\
\hline & Water & Ethylene glycol & & & & & \\
\hline $\mathrm{COL}$ & 67.00 & 27.81 & 101.23 & 43.46 & 11.5 & 31.95 & 15.02 \\
\hline PET & 131.84 & 26.83 & 24.23 & 290.25 & 65.64 & 224.61 & 107.38 \\
\hline PET-COL-RIBO & 24.94 & 17.96 & 138.81 & 76.49 & 73.38 & 3.10 & 10.48 \\
\hline
\end{tabular}
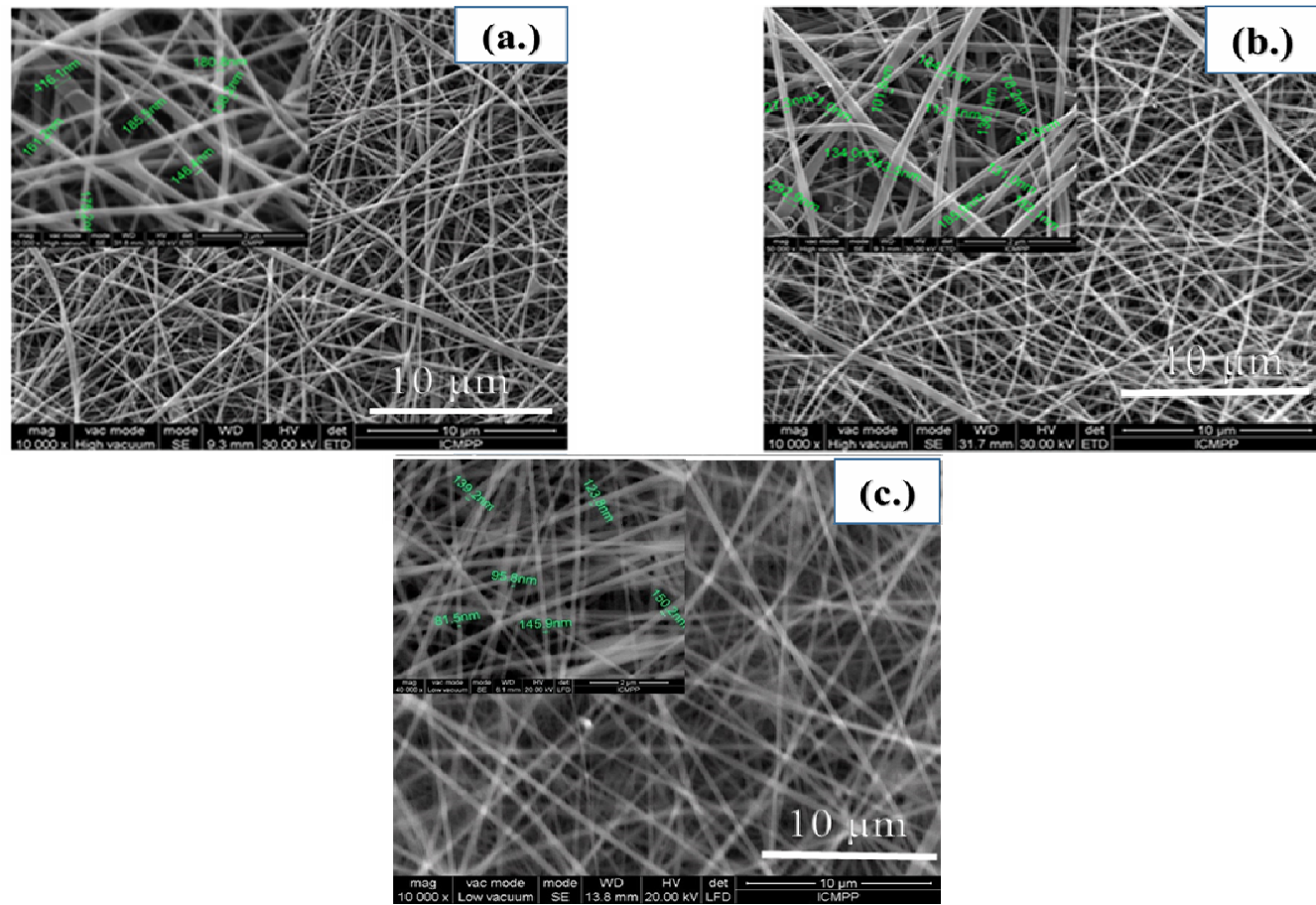

Figure 1: SEM morphology of nanofibers: (a) COL, (b) PET and (c) PET-COL-RIBO 
Collagen

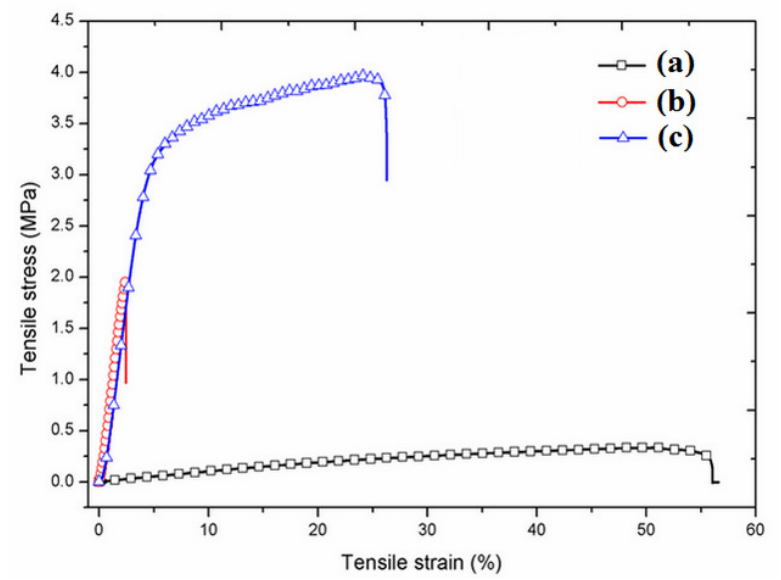

Figure 2: Stress-strain curves for nanofibers: (a) COL, (b) PET and (c) PET-COL-RIBO

\section{Mechanical properties of nanofibers}

Mechanical properties play an important role in the evaluation of nanofibers. Therefore, the mechanical properties of the prepared nanofibers were investigated. The mechanical properties of the nanofiber samples were influenced by the cross-linking ability.

From the stress-strain graph, the tensile toughness can be calculated. This parameter represents the amount of energy per volume, and can be easily calculated using the area under the stress-strain curve. The tensile strength indicates how much force the material can support, and tensile toughness indicates how much energy a material can absorb before breaking. It is noticed that COL has the smallest deformation energy $\left(2.35 \mathrm{MJ} / \mathrm{m}^{3}\right)$, denoting a material with enhanced brightness. PET has a medium value of deformation energy $\left(12.03 \mathrm{MJ} / \mathrm{m}^{3}\right)$, while the combination of PET with COL and RIBO as cross-linker has the highest amount (87.25 $\mathrm{MJ} / \mathrm{m}^{3}$ ). It can be seen that PET-COL-RIBO combines the properties of the original materials and gains quality by a high breaking resistance (3.947 MPa), compared with PET $(0.297 \mathrm{MPa})$ or COL (1.945 MPa).

The mechanical properties of PET-COL-RIBO were investigated and compared to those of PET and COL nanofibers. Uniaxial tensile strength measurements of PET-COL-RIBO nanofibers showed an increase in Young's modulus after the UV treatment, compared to the measurements obtained for COL and PET. Elongation at break was $~ 56 \mathrm{GPa}$ for the PET sample, with the nanofiber diameter varying between $80-500 \mathrm{~nm}$, which is greater than that of COL, with the nanofiber diameter of $120-450 \mathrm{~nm}$, and that of PET-COL-RIBO, with nanofiber diameter of 150$250 \mathrm{~nm}$. Fiber diameter and tensile strength are the dominant factors for PET nanofibers, which are expected to have better performance than COL nanofibers and PET-COL-RIBO.

An important reason for the relatively poor mechanical properties of electrospun nanofibers lies in the fact that it is nearly impossible to achieve longer chains during the electrospinning process. $^{23}$ The mechanical properties were not ascribed to the increase of crystallinity through the fast formation of the nanofibers that resulted from the rapid evaporation of the solvent. It was proposed that the increase in mechanical properties was mainly related to the confined molecular orientation of the amorphous regions with decreasing nanofiber diameter. ${ }^{24}$ The values listed in Table 2 result from the structure and orientation of the nanofibers.

\section{Microstructure of nanofibers \\ Fourier Transform Infrared-Attenuated Total Reflectance Spectroscopy (FTIR-ATR)}

The electrospun films were investigated structurally using FTIR-ATR spectroscopy. The FTIR-ATR spectra of COL, PET and PET-COLRIBO, respectively, are shown in Figure 3.

Figure 3a illustrates the FTIR-ATR spectrum of the COL sample. The characteristic peaks of the collagen structure are located at 1454, 1404, $1334,1282,1240$ and $1205 \mathrm{~cm}^{-1}$, and are assigned to the vibrations of $\delta(\mathrm{CH} 2), \delta(\mathrm{CH} 3), v(\mathrm{CN})$, $\delta(\mathrm{NH})$. The characteristic bands corresponding to amide A $\left(3295 \mathrm{~cm}^{-1}\right)$ and amide B $\left(3067 \mathrm{~cm}^{-1}\right.$ stretching $\mathrm{C}-\mathrm{H})$ were also identified. ${ }^{25}$ 
Table 2

Mechanical properties of nanofibers

\begin{tabular}{lcccc}
\hline Samples & $\begin{array}{c}\text { Young's modulus } \\
(\mathrm{MPa}) \cdot 10^{-3}\end{array}$ & $\begin{array}{c}\text { Elongation at } \\
\text { break }(\%)\end{array}$ & $\begin{array}{c}\text { Breaking resistance } \\
(\mathrm{MPa})\end{array}$ & $\begin{array}{c}\text { Toughness at break } \\
\left(\mathrm{MJ} / \mathrm{m}^{3}\right)\end{array}$ \\
\hline PET & 1.02 & 55.96 & 0.30 & 12.03 \\
COL & 87.31 & 2.44 & 1.95 & 2.35 \\
PET-COL-RIBO & 79.68 & 26.18 & 3.95 & 87.25 \\
\hline
\end{tabular}

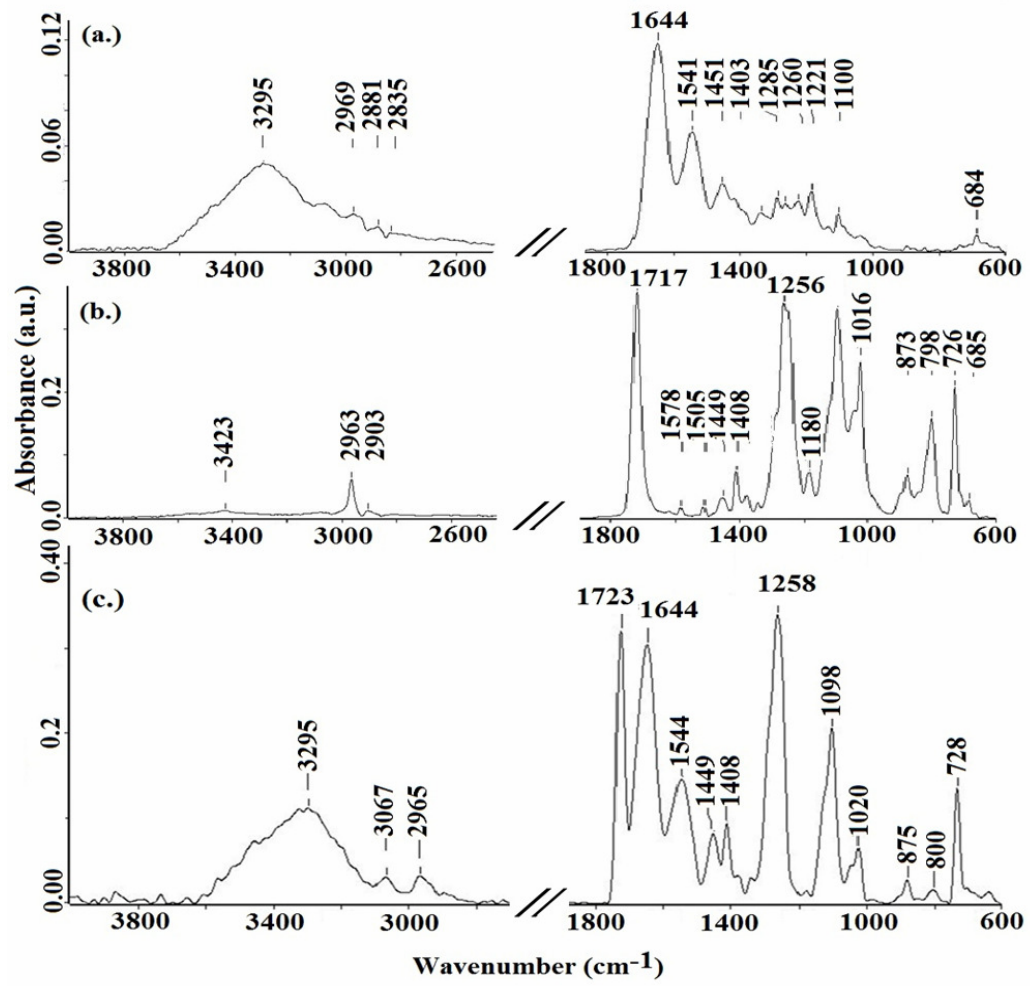

Figure 3: FTIR-ATR spectra of nanofibers obtained by electrospinning from (a) COL and (b) PET and (c) PET-COL-RIBO

In addition, three vibrations corresponding to the amide from collagen were observed, the one located at $1644 \mathrm{~cm}^{-1}$ was attributed to the amide I band (due to $v(\mathrm{C}=\mathrm{O})$ stretching); another one at $1551 \mathrm{~cm}^{-1}$ attributed to the amide II band - mainly represented by the $\delta(\mathrm{NH})$ bond deformation vibrations and stretching vibration of the $v(\mathrm{CN})$ bond from the amide groups, and one at $1221 \mathrm{~cm}^{-}$ ${ }^{1}$ corresponding to amide III (due to the $v(\mathrm{CN})$ vibration and $\delta(\mathrm{NH})$ deformation $){ }^{26}$ The vibration band at $1451 \mathrm{~cm}^{-1}$ corresponds to the $\mathrm{C}=\mathrm{H}$ stretching (from proline and hydroxyproline) and that at $1334 \mathrm{~cm}^{-1}$ to the stereochemistry of proline and hydroxyproline. The absorptions between $3100-3400 \mathrm{~cm}^{-1}$ are due to the $\mathrm{vOH}$ and $v \mathrm{NH}$ stretching vibration bands present in amide $\mathrm{A} .^{27-29}$

Figure 3(b) illustrates the FTIR-ATR spectrum of the PET structures, namely $-\mathrm{C}_{6} \mathrm{H}_{4}-\mathrm{COO}-\mathrm{CH}_{2}-$ $\mathrm{CH}_{2}$ - group in gauche or trans configurations.
Thus, the bands at 1341 and $1373 \mathrm{~cm}^{-1}$ are attributed to the wagging vibrations of the $-\mathrm{CH}_{2}$ $\mathrm{CH}_{2}$ groups from ethylene glycol in trans and gauche conformations. ${ }^{30}$ The peak at $1408 \mathrm{~cm}^{-1}$ corresponds to the vibration deformation of the phenylene ring $(\delta \mathrm{CH})$ coupled with the stretching band $v(\mathrm{C}=\mathrm{C}){ }^{31}$ The stretching vibrations $\mathrm{v}(\mathrm{C}=\mathrm{O})$ derived from the ester group of the polyethylene terephthalate structure, generating a band with the maximum at $1717 \mathrm{~cm}^{-1}$. The characteristic bands of gauche conformers are located at $1452 \mathrm{~cm}^{-1}\left(\delta\left(\mathrm{CH}_{2}\right)\right), 1180 \mathrm{~cm}^{-1}\left(\mathrm{CH}_{2}\right)$, $1016 \mathrm{~cm}^{-1}(\mathrm{CO})$ and $898 \mathrm{~cm}^{-1}\left(\mathrm{CH}_{2}\right)$, respectively.

The peaks at 2963 and $2902 \mathrm{~cm}^{-1}$ are attributed to the stretching vibrations $\mathrm{vCH}_{2}$ (asim and sim) derived from the PET structures in gauche conformation.

The FTIR-ATR spectrum of PET-COL-RIBO is shown in Figure 3 (c). Thus, amide I, amide II 
and amide III vibration bands from the collagen structure appear at 1644, 1544 and $1449 \mathrm{~cm}^{-1}$, respectively.

The characteristic bands of PET chain are located at $1408 \mathrm{~cm}^{-1}\left(\delta\left(\mathrm{CH}_{2}\right)\right), 1373 \mathrm{~cm}^{-1} \mathrm{w}\left(\mathrm{CH}_{2}\right)$, $1180 \mathrm{~cm}^{-1}\left(\mathrm{CH}_{2}\right), 1016 \mathrm{~cm}^{-1}(\mathrm{CO})$ and $898 \mathrm{~cm}^{-1}$, respectively.

The bands between $1322-1338 \mathrm{~cm}^{-1}$ are assigned to the deformation vibrations of the $\mathrm{CH}_{2}$ groups and show a relative increase due to the cross-linking effect. The peak around 1250 $\mathrm{cm}^{-1}$ is due to the presence of RIBO in the PETCOL-RIBO sample, and the band characteristic to the carbonyl group was moved at $1723 \mathrm{~cm}^{-1}$.

In conclusion, FTIR-ATR spectroscopy analysis revealed hydrogen bonding interactions that occurred between the carbonyl groups $(\mathrm{C}=\mathrm{O})$ of RIBO and the amino groups $\left(-\mathrm{NH}_{2}\right)$ of collagen. $^{32,33}$

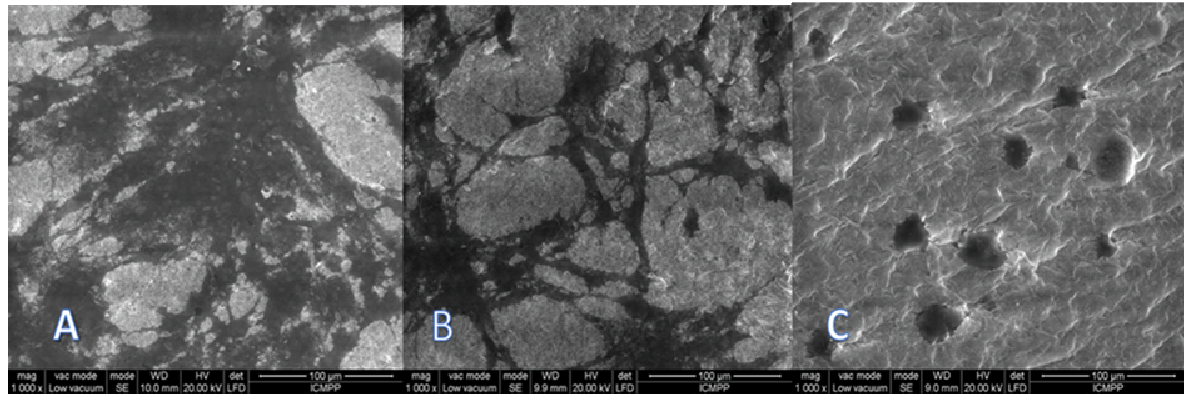

Figure 4: SEM images of proliferated fibroblast cells on (A) COL, (B) PET and (C) PET-COL-RIBO nanofibers after $72 \mathrm{~h}$

\section{Cell morphology}

SEM images of the gold sputter-coated nanofiber samples, populated with cells, are shown in Figure 4 (A, B and C). It can be observed that all the materials present cells on their surfaces. However, the cell morphology is different on the three materials, COL, PET and PET-COL-RIBO. As observed in Figure 4, the cells on COL and PET show higher density, compared to those on PET-COL-RIBO. The most populated surface is noted on the COL sample, followed by PET. The higher capacity of the COL sample to ensure cell growth can be explained by the properties of collagen, which provide higher density of the cell attachment moieties. It should be noted that the cells on both COL and PET surfaces have typical fibroblast morphology, with a large distribution of thin protuberances along the length of the nanofibers. On the surface of PET-COL-RIBO, poor cell population can be observed, with low density and rounded morphology.

\section{CONCLUSION}

Nanofibers based on COL, PET and PETCOL-RIBO were fabricated by the electrospinning technique, using HFIP as solvent. Under optimum conditions, the PET-COL-RIBO nanofibers exhibited uniform and porous structure, with fiber diameters in the range of 150$250 \mathrm{~nm}$, similar to those of COL nanofibers. After cross-linking, these nanofibers exhibited good mechanical properties, in comparison with COL or PET nanofibers. The interaction between the nanofiber materials and fibroblast cells was assessed, and the results obtained were satisfactory. It should be noted that the covered cells on both COL and PET surfaces had typical fibroblast morphology, with a large distribution of thin protuberances along the length of the nanofibers. Meanwhile, on the surface of PETCOL-RIBO, poor cell population could be observed, with low density and rounded morphology.

ACKNOWLEDGEMENTS: The authors acknowledge financial support of the research through the Project "Partnerships for knowledge transfer in the field of polymer materials used in biomedical engineering", ID P_40_443, Contract no. 86/8.09.2016, SMIS 105689, co-financed by the European Regional Development Fund by the Competitiveness Operational Program 2014-2020, Axis 1: Research, technological development and innovation in support of economic competitiveness and business development, Action 1.2.3. Knowledge transfer partnerships". 


\section{REFERENCES}

M. Mândru, S. Vlad, C. Ciobanu, L. Lebrun and M. Popa, Cellulose Chem. Technol., 47, 5 (2013), http://www.cellulosechemtechnol.ro/pdf/CCT12(2013)/p.5-12.pdf

2 M. Schindler, I. Ahmed and J. A. Kamal, Biomaterials, 26, $5624 \quad$ (2005), https://doi.org/10.1016/j.biomaterials.2005.02.014

3 S. Vlad, L. M. Gradinaru, C. Ciobanu, D. Macocinschi, D. Filip et al., Cellulose Chem. Technol., 49. 905

(2015),

http://www.cellulosechemtechnol.ro/pdf/CCT910(2015)/p.905-913.pdf

4 R. E. David and J. W. Jiann, Top. Curr. Chem., 247, 207 (2005).

5 A. Jaworek and A. Sobczyk, J. Electrostat., 66, 197 (2008), https://doi.org/10.1016/j.elstat.2007.10.001

6 G. C. Rutledge and S. V. Fridrikh, Adv. Drug Deliv. $\quad$ Rev., $\quad 59, \quad 1384 \quad$ (2007), https://doi.org/10.1016/j.addr.2007.04.020

7 W. E. Teo and S. Ramakrishna, Nanotechnology, 17, 89 (2006), https://doi.org/10.1088/09574484/17/14/R01

8 M. Gibril, T. Tesfaye, B. Sithole, P. Lekha and D. Ramjugernath, Cellulose Chem. Technol., 52, 711 (2018),

http://www.cellulosechemtechnol.ro/pdf/CCT910(2018)/p.711-727.pdf

9 C. Jia, S. He, J. Song, Y. Jin, W. Zhu et al., Cellulose Chem. Technol., 51, 693 (2017), http://www.cellulosechemtechnol.ro/pdf/CCT78(2017)/p.693-701.pdf

10 K. P. Ramesh, N. Khan, S. Vivekanandhan, N. Satyanarayana, A. Mohanty et al., J. Nanosci. Nanotechnol., 12, 1 (2012).

11 A. L. Yarin, S. Koombhongse and D. H. Reneker, J. Appl. Phys., 90, $4836 \quad$ (2001), https://doi.org/10.1063/1.1408260

12 S. K. Park, H. Yoon, J. Gon Son, T. Min and G. H. Kim, Polym. Int., 56, 1361 (2007), https://onlinelibrary.wiley.com/doi/pdf/10.1002/pi.234 5

13 W. F. Zheng, W. Zhang and X. Y. Jiang, Adv. Eng. Mater., $\quad$ 12, B451 https://doi.org/10.1002/adem.200980087

14 S. Zhong, W. E. Teo, X. Zhu, R. W. Beuerman, S. Ramakrishna et al., J. Biomed. Mater. Res., 79A, 456 (2006), https://doi.org/10.1002/jbm.a.30870

15 Y. Z. Zhang, J. Venugopal, Z. M. Huang, C. T. Lim and S. Ramakrishna, Biomacromolecules, 6, 2583 (2005), https://doi.org/10.1021/bm050314k

16 S. J. Kew, J. H. Gwynne, D. Enea, M. Abu-Rub, A. Pandit et al., Acta Biomater., 7, 3237 (2011), https://doi.org/10.1016/j.actbio.2011.06.002
17 I. K. Kwon and T. Matsuda, Biomacromolecules, 6 , 2096 (2005), https://doi.org/10.1021/bm050086u

18 I. Z. Dimitrios, R. Gordon and P. Geoffrey, J. Biomed. Mater. Res., 89A, $896 \quad$ (2009), https://doi.org/10.1002/jbm.a.32031

19 A. Scott McCall, S. Kraft, H. F. Edelhauser, G. W. Kidder, R. L. Richard et al., IOVS, 51, 1 (2010), DOI: 10.1167/iovs.09-3738

${ }^{20}$ L. A. Hapach, J. A. VanderBurgh, J. P. Miller and C. A. Reinhart-King, Phys. Biol., 12, 061002 (2015), https://doi.org/10.1088/1478-3975/12/6/061002

21 H. Y. Erbil, "Surface Chemistry of Solid and Liquid Interfaces", Oxford, Wiley Blackwell, England, 2006, pp. 368-370.

22 K. L. Menzies and L. Jones, Optom. Vis. Sci., 87, 387 (2010), DOI: 10.1097/OPX.0b013e3181da863e

23 C. J. van Oss, "Interfacial Forces in Aqueous Media”, Dekker, New York, 1994.

24 A. Greiner and J. H. Wendorff, Angew. Chem. Int. Ed., 46, $\quad 5670 \quad$ (2007), https://doi.org/10.1002/anie.200604646

25 D. Li and Y. Xia, Adv. Mater., 16, 1151 (2004), https://doi.org/10.1002/adma.200400719

26 S. B. Botta, P. A. Ana, M. O. Santos, D. M. Zezell and A. B. Matos, J. Biomed. Mater. Res., B, 100B, 1009 (2012), https://doi.org/10.1002/jbm.b.32666

27 R. J. Jakobsen, L. L. Brown, T. B. Hutson, D. J. Fink and A. Veis, Science, 220, 1288 (1983), DOI: $10.1126 /$ science. 6857249

28 A. Sionkowka, M. Wisniewski, J. Skopinska, C. J. Kennedy and T. J. Wess, Biomaterials, 25, 795 (2004), https://doi.org/10.1016/S0142-9612(03)00595-7

${ }^{29}$ L. Duan, J. Yuan, X. Yang, X. Cheng and J. Li, Int. J. Biol. Macromol., 93, 468 (2016), https://doi.org/10.1016/j.ijbiomac.2016.09.003

${ }^{30}$ Z. Chen, J. N. Hay and M. J. Jenkins, Eur. Polym. J., 48, $\quad 1586 \quad$ (2012), https://doi.org/10.1016/j.eurpolymj.2012.06.006

31 C. Pellerin, M. Pézolet and P. R. Griffiths, Macromolecules, 39, $6546 \quad$ (2006), https://doi.org/10.1021/ma0610459

32 G. B. Jung, H. J. Lee, J. H. Kim, J. I. Lim, S. Choi et al., J. Nanosci. Nanotechnol., 16, 71 (2014).

33 N. Beztsinna, M. Sol, N. Taib and I. Bestel, Biomaterials, $\quad 80, \quad 121 \quad$ (2016), https://doi.org/10.1016/j.biomaterials.2015.11.050 